\title{
EWSR1/PATZ1 Fusion Gene Long A Isoform
}

National Cancer Institute

\section{Source}

National Cancer Institute. EWSR1/PATZ1 Fusion Gene Long A Isoform. NCI Thesaurus.

Code C99240.

A fusion gene $(\sim 2.2 \mathrm{~kb})$ that results from a chromosomal inversion inv(22)(q12q12)

which fuses the first eight exons of the EWSR1 gene with the PATZ1 gene. This rearrangement is associated with Ewing tumor/peripheral primitive neuroectodermal tumor. 